\title{
A Retrospective Study of CNS Tumors
}

\author{
Dr.Joel Dhanapandian $\mathrm{S}^{1}$, Dr.Johnsy Merla $\mathbf{J}^{2}$, \\ ${ }^{1}$ Associate Professor, Department Of Neurosurgery, Tirunelveli Medical College. ${ }^{2}$ Assistant Professor, \\ Department Of Pathology, Tirunelveli Medical College. \\ The Tamilnadu Dr.M.G.R Medical University, India)
}

\begin{abstract}
A total of 50 patients with CNS tumors were evaluated clinically and by imaging techniques followed by intraoperative examination and histopathological evaluation of the resected tumor. The age of the patients ranged from 5 to 70 years with a peak between 30 and 50 years. Overall, males were more frequently affected than females, the male: female ratio being $1.4: 1$. CNS neoplasms occurred predominantly intracranially 42 cases (84\%), whereas the remaining 8 cases (16\%) were spinal (ratio: $5.25: 1)$ The commonest presenting symptoms were headache, motor weakness and seizures. Frontal lobe was the commonest intracranial site (37.5\%) and dorsal region the most frequently involved site in spinal cord tumors. Regarding the imaging studies the overall accuracy rate of MRI was $70 \%$, in these cases. Biopsy was regarded as the sole means of confirming the presumptive clinical diagnosis. Histologically, of the CNS tumors, meningiomas constituted the maximum number of cases, 18 cases (42.8\%) followed by astrocytoma( 33.3\%). Among the spinal tumors schwannoma constituted $50 \%$ of cases. In this study, an effort was made to provide a current overview of the central nervous system tumors in a tertiary care hospital set up.
\end{abstract}

Keywords: CNS Tumors, Infratentorial, Spinal, Supratentorial.

\section{Introduction}

Central nervous system neoplasms represent a unique, heterogeneous population of neoplasms and include both benign and malignant tumors. Central nervous system (CNS) tumors comprise $2 \%$ to $5 \%$ of all tumors. In India, tumors of the CNS constitute about 1.9\% of all tumors (1). $60 \%$ to $80 \%$ of brain tumors are primary and rest $20 \%$ to $40 \%$ are metastatic (2). Heritable syndromes and ionizing radiations are the only two established causes of primary CNS neoplasms (3). $80 \%$ involve the brain and $20 \%$ involve the spinal cord. The age distribution of CNS tumors is said to be bimodal, one peak in children, then second peak in 45-70 years of age (4). Tumors of the CNS account for as many as $20 \%$ of all cancers of childhood and next to leukemia as a cause of death. In childhood, $70 \%$ of primary brain tumors are infratentorial and involve cerebellum, midbrain, Pons and medulla (5). Male predilection has been described in most cases (6), the only exception being meningioma (7). The signs and symptoms of intracranial tumors depend on the size of tumor, its location and its rate of growth. The malignant tumors grow more rapidly and are associated with a shorter survival. The overall clinical experiences indicate that the incidence of brain tumors is not low. The majority of patients die within the first year of diagnosis of malignant lesion and less than 3\% survive more than 3 years (8). Hence analysis of CNS neoplasm's will provide knowledge for better diagnosis and management.

\section{Materials And Methods}

This retrospective study was done in the Neurosurgery department of Tirunelveli medical college for a period of 5 years. A total number of 50 patients with diagnosis of CNS tumor were included in this study. Data on clinical presentation, radiological features and histopathological diagnosis of all cases were collected from the patients' records.

\section{Results}

Patient's age ranged from 5 to 70 years with a peak between 30 and 50 years.

Table 1: Gender distribution

\begin{tabular}{|l|l|l|}
\hline Gender & No. Of Cases & Percentage \\
\hline Male & 29 & 58 \\
\hline Female & 21 & 42 \\
\hline
\end{tabular}




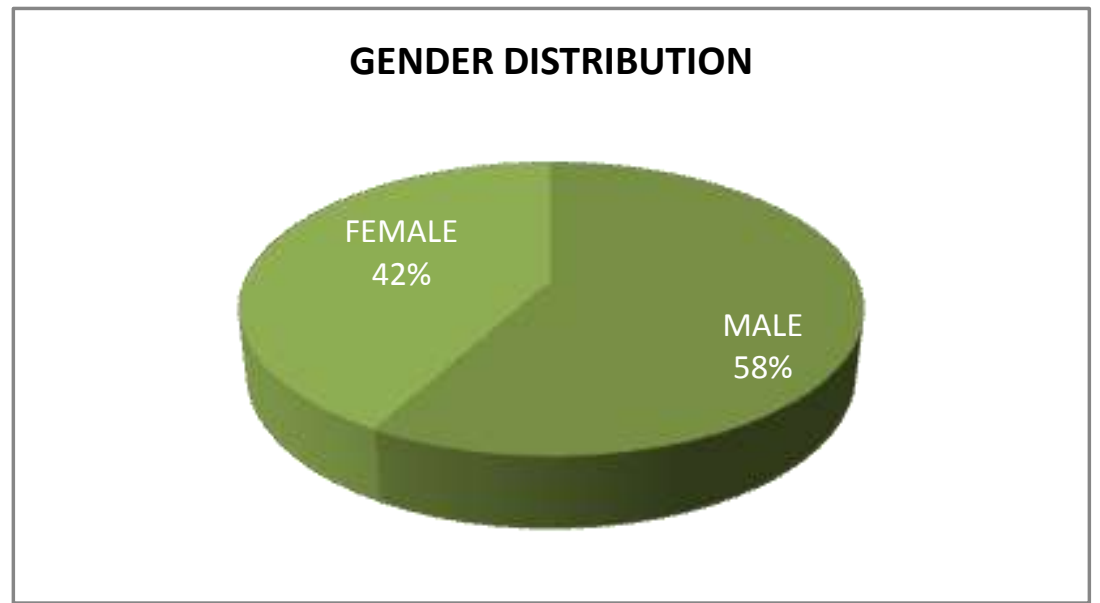

Figure 1: Gender distribution

In our study, there were $29(58 \%)$ males and $21(42 \%)$ females with 1.4:1 male to female ratio (Table $1 \&$ Figure 1).

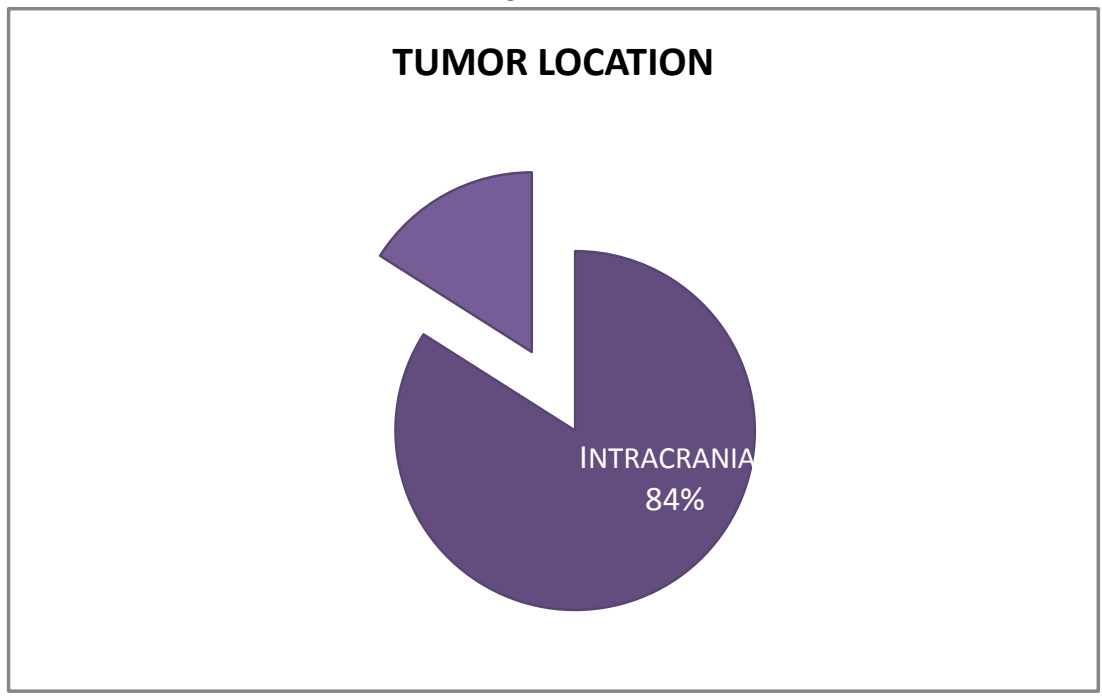

Figure 2: Location of CNS tumors

The majority of cases were intracranial 42 cases $(84 \%)$, whereas the remaining 8 cases $(16 \%)$ were spinal (ratio: 5.25 :1) (Figure 2)

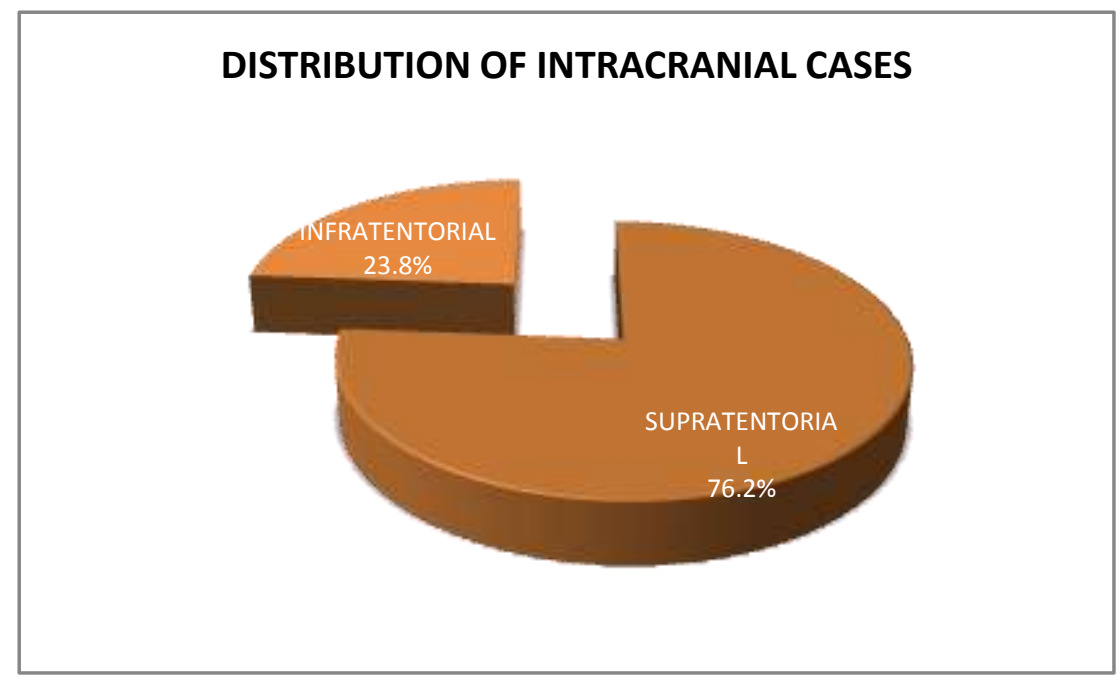

Figure 3: Distribution of Intracranial cases 
Of the 42 intracranial cases, 32 cases $(76.2 \%)$ were supratentorial and 10 cases $(23.8 \%)$ were infratentorial (Figure 3)

Table 2: Distribution of Supratentorial cases

\begin{tabular}{|l|l|l|l|}
\hline S.No & Location & No.Of Cases & Percentage \\
\hline 1 & Frontal & 12 & 37.5 \\
\hline 2 & Parietal & 3 & 9.37 \\
\hline 3 & Temporoparietal & 3 & 9.37 \\
\hline 4 & Suprasellar & 3 & 9.37 \\
\hline 5 & Frontoparietal & 3 & 9.37 \\
\hline 6 & Temporal & 2 & 6.25 \\
\hline 7 & Parasagittal & 2 & 6.25 \\
\hline 8 & Occipital & 1 & 3.13 \\
\hline 9 & Falx & 1 & 3.13 \\
\hline 10 & Thalamic & 1 & 3.13 \\
\hline 11 & Parasagittal & 1 & 3.13 \\
\hline
\end{tabular}

Of the supratentorial tumors, there were 12 cases (37.5\%) frontal, 3 cases $(9.37 \%)$ each of parietal, temporoparietal, suprasellar and frontoparietal tumors. 2 cases $(6.25 \%)$, temporal, parasagittal and $1(3.13 \%)$ case, each of Occipital, falx, Thalamic, Parasagittal location (Table 2 \& Figure 4).

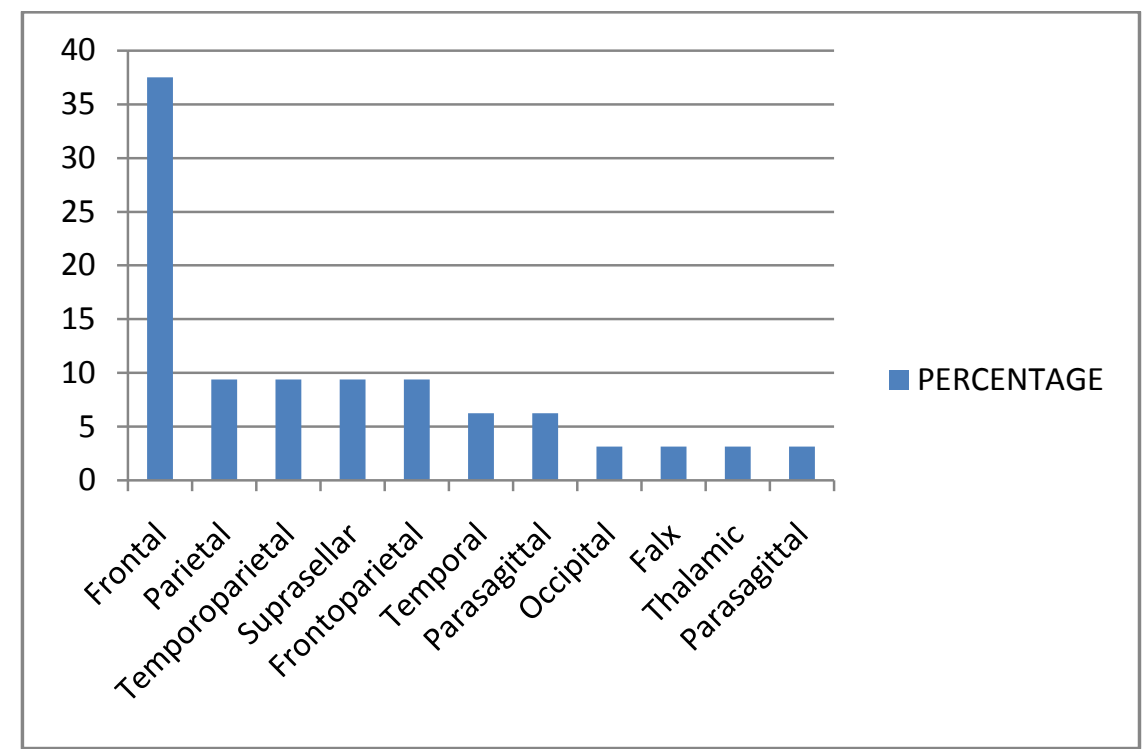

Figure 4: Distribution of Supratentorial cases

Infratentorial cases were equally distributed in cerebellar and cerebellopontine regions 5 cases each $(50 \%)$. (Table 3 \& Figure 5).

Table 3: Distribution of Infratentorial cases

\begin{tabular}{|l|l|l|l|}
\hline S.No & Location & No.Of Cases & Percentage \\
\hline 1 & Cerebellar & 5 & 50 \\
\hline 2 & Cerebellopontine & 5 & 50 \\
\hline
\end{tabular}

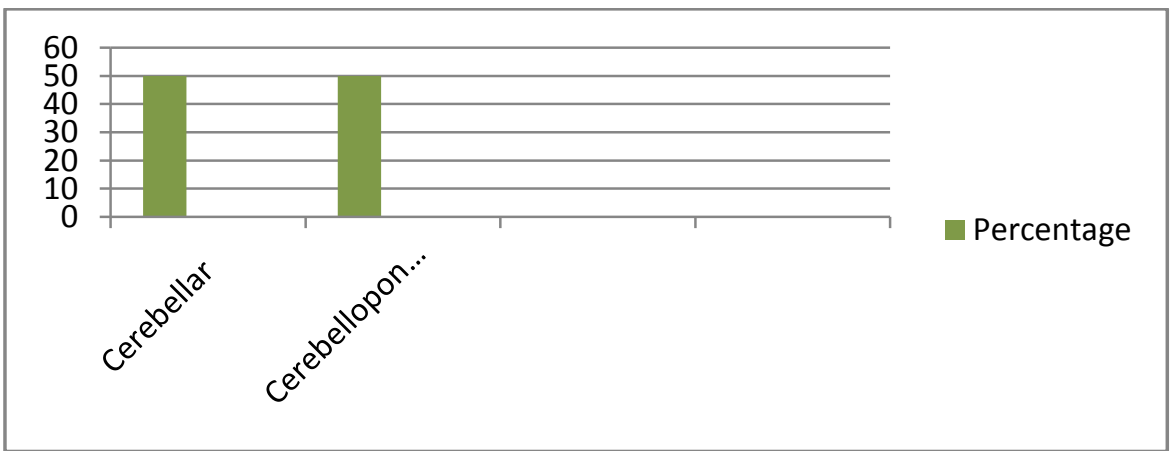

Figure 5: Distribution of Infratentorial cases 
Table 4: Histological types of intracranial lesions

\begin{tabular}{|l|l|l|l|}
\hline S.No & Histological Type & No.Of Cases & Percentage \\
\hline 1 & Meningioma & 18 & 42.8 \\
\hline 2 & Astrocytoma & 14 & 33.3 \\
\hline 3 & Medulloblastoma & 3 & 7.1 \\
\hline 4 & Schwannoma & 2 & 4.8 \\
\hline 5 & Craniopharyngioma & 1 & 2.4 \\
\hline 6 & Epidermoid & 1 & 2.4 \\
\hline 7 & Oligodendroglioma & 1 & 2.4 \\
\hline 8 & Gangliocytoma & 1 & 2.4 \\
\hline 9 & Tuberculoma & 1 & 2.4 \\
\hline
\end{tabular}

Histologically, of the CNS tumors Meningiomas constituted the maximum number of cases, 18 cases $(42.8 \%)$ followed by Astrocytoma (33.3\%). There were 3 cases (7.1\%) of Medulloblastoma, 2 cases (4.8\%) Schwannoma, and 1 case (2.4\%) each of Craniopharyngioma, Epidermoid, Oligodendroglioma, Gangliocytoma and Tuberculoma. ( Table 4)

\section{Spinal Tumors}

In our study, there were 8 cases $(16 \%)$ of spinal tumors, and was equally distributed between males and females 4 cases $(50 \%)$ each, with 1:1 male to female ratio

Table 5: Histological types of spinal tumors

\begin{tabular}{|l|l|l|l|}
\hline S.No & Tumor & No.Of Cases & Percentage \\
\hline 1 & Schwannoma & 4 & 50 \\
\hline 2 & Pnet & 1 & 12.5 \\
\hline 3 & Psammomatous Meningioma & 1 & 12.5 \\
\hline 4 & Neurofibroma & 1 & 12.5 \\
\hline 5 & Hemangioma & 1 & 12.5 \\
\hline
\end{tabular}

There were 4 cases (50\%) of Schwannoma, and 1 case (12.5\%) of PNET, Psammomatous Meningioma, Neurofibroma, Hemangioma. (Table 5) In our study of CNS tumors, the most common clinical symptoms were headache, seizures and vomiting related to raised intracranial pressure (ICP). Convulsion and focal neurological deficits (FND) were more common in patients with supratentorial tumors. In patients with infratentorial tumors, vertigo, hydrocephalus and raised ICP were the presenting symptoms. All patients with spinal tumors presented with backache. Other presenting symptoms were weakness and paresthesia. The common radiological findings in CNS tumors were mass lesions with pressure effect on adjacent structures and peritumoral edema. Regarding the imaging studies the overall accuracy rate of MRI was $70 \%$, in these cases. Biopsy was regarded as the sole means of confirming the presumptive clinical diagnosis.

\section{Discussion}

Among the 50 cases of brain tumor in our study, we found that the patients age ranged from 5 to 70 years with a peak between 30 and 50 years. Our finding was similar to the finding of Mondal S et al (9), Masoodi et al (10) and Dhar et al. (11). In our study, there were 29 (58\%) males and 21 (42\%) females with 1.4:1 male to female ratio. Masoodi et al., and Ghanghoria et al. (12), found a similar sex ratio in their study. Frontal lobe was the commonest intracranial site $(37.5 \%)$ and dorsal region the most frequently involved site in spinal cord tumors. Our study was comparable to the finding of Masoodi et al. (10), Jamal et al (13), and Jalali etal. (14).

The most common symptoms in the patients in our study were headache, similar to other studies $(9,10)$. Histologically, of the CNS tumors, Meningiomas constituted the maximum number of cases, 18 cases $(42.8 \%)$ similar to study by Ghanghoria et al (12), and Lee et al. (15), followed by Astrocytoma (33.3\%). In a study by Mondal s et al (9), Neuroepithelial tumor was most common (70.76\%) and astrocytoma was the most common subtype (41.5\%) whereas Meningiomas (20 cases, $15.3 \%$ ) were the second common type of CNS tumor. In our study, among the spinal tumors schwannoma constituted $50 \%$ of cases.

The imaging modalities, using MRI and CT-scan, were proved to be of a particular importance for provisional diagnosis. They provide important information that aid in the determination of the type and location of the tumors. Regarding the imaging studies the overall accuracy rate of MRI was $70 \%$, comparable to a study by Intisar (16), in which the accuracy rate was (69.3\%). Biopsy was regarded as the sole means of confirming the presumptive clinical diagnoses.

\section{Conclusion}

Accurate diagnosis of CNS tumors requires sophisticated modern invasive and noninvasive techniques such as radiological imaging, intraoperative squash cytology and histopathological examination. 
Histopathological diagnosis was regarded as the sole means of confirming the presumptive clinical diagnosis and is necessary for the formulation of further management after neurosurgery. Introduction of advanced imaging techniques for better diagnostic purposes and implementing adequate investigation programs like immunohistochemical tests and chromosomal analysis are essential for exact diagnosis.

\section{References}

[1]. Tamkeen Masoodi, Ram Kumar Gupta, J. P. Singh, Arvind Khajuria. Pattern of central nervous system neoplasms: a study of 106 cases jk- Practitioner Vol.17, No. 4 October-December 2012

[2]. Rubin P, Mc Donald S, Qazi R. Clinical oncology, 7th edition. Philadelphia: WE Saunders; 1993.

[3]. Preston-Martin S. Epidemiology of Primary CNS 19. Lee CH, Jung KW, Yoo H, et al. Epidemiology of neoplasms. Neurol Clin 1996; 14 (2): 273-90.

[4]. Lantos PL, Louis DN, Rosenblum MK, et al. Tumors of the nervous system. In: Graham DI, Lantos PL, Eds, Greenfield's Neuropathology, 7th Ed., Arnold, London, 2002.

[5]. Burger PC, Scheithauer BW, Vogel FS. Surgical pathology of nervous system and its covering, 3rd edition. New York: Churchill Livingstone; 1991.

[6]. Epidemiology research group. Epidemiologic investigation of brain tumors among employees at Chevron Texaco La Harba Corporate Petroleum Research facility. Chevron Texaco-Research. 2004;11:1-140.

[7]. Ghosh S. Primitive neuroectodermal tumors of the central nervous system. EMedicine World Medical Library. 2001; 14: 1-9.

[8]. Yeole BB. Trends in the Brain Cancer Incidence in India. Asian Pac J Cancer Prev 2008;9:267-70.

[9]. Mondal S, Pradhan R, Pal S, Biswas B, Banerjee A, Bhattacharyya D. Clinicopathological pattern of brain tumors: A 3-year study in a tertiary care hospital in India. Clin Cancer Investig J 2016;5:437-40

[10]. Masoodi T, Gupta RK, Singh JP, Khajuria A. Pattern of central nervous system neoplasm: A study of 106 cases. JK Pract 2012;17:42-6

[11]. Dhar A, Bhat AR, Nizami FA, Kirmani AR, Zargar J, Ramzan AU, et al. Analysis of brain tumors in Kashmir Valley. A 10 year study. Bangladesh J Med Sci 2014;13:268-77.

[12]. Ghanghoria S, Mehar R, Kulkarni CV, Mittal M, Yadav A, Patidar H. Retrospective histological analysis of C S tumors - A 5 year study. Int J MED Sci Public Health 2014;3:1205-7.

[13]. Jamal S, Moghal S, Mamoon N, Mushtaq S, Luqman M, Anwar M. The pattern of malignant tumors, Tumor registry data analysis AFIP, Rawalpindi, Pakistan (1992-2001). JPak MedAssoc 2006;56:359-62.

[14]. Jalali R, Datta D. Prospective analysis of incidence of central nervous tumors presenting in a tertiary care hospital from India. JNeurooncol 2008;87:111-4.

[15]. Lee CH, Jung KW, Yoo H, Park S, Lee SH. Epidemiology of primary brain and central nervous system tumors in Korea. J Korean Neurosurg Soc 2010;48:145-52.

[16]. Intisar s.h. Patty.Central nervous system tumors a clinicopathological study Kurdistan 1st conference on biological sciences j. dohuk Univ., vol. 11, no. 1, 2008.

Figure 6: MRI - Sagittal \& Axial section of spinal cord tumor - intradural extramedullary lesion at L1.

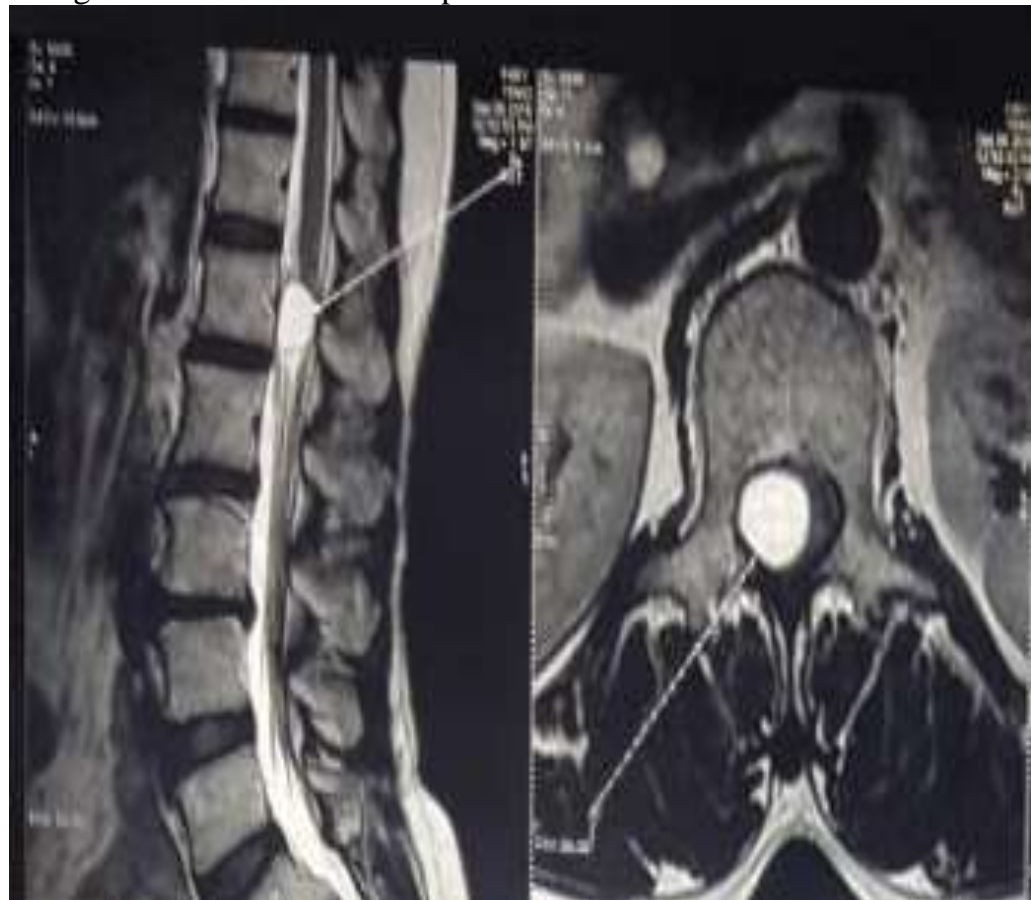


Figure 7: MRI Axial section showing contrast enhancing CP angle Tumor (Meningioma)

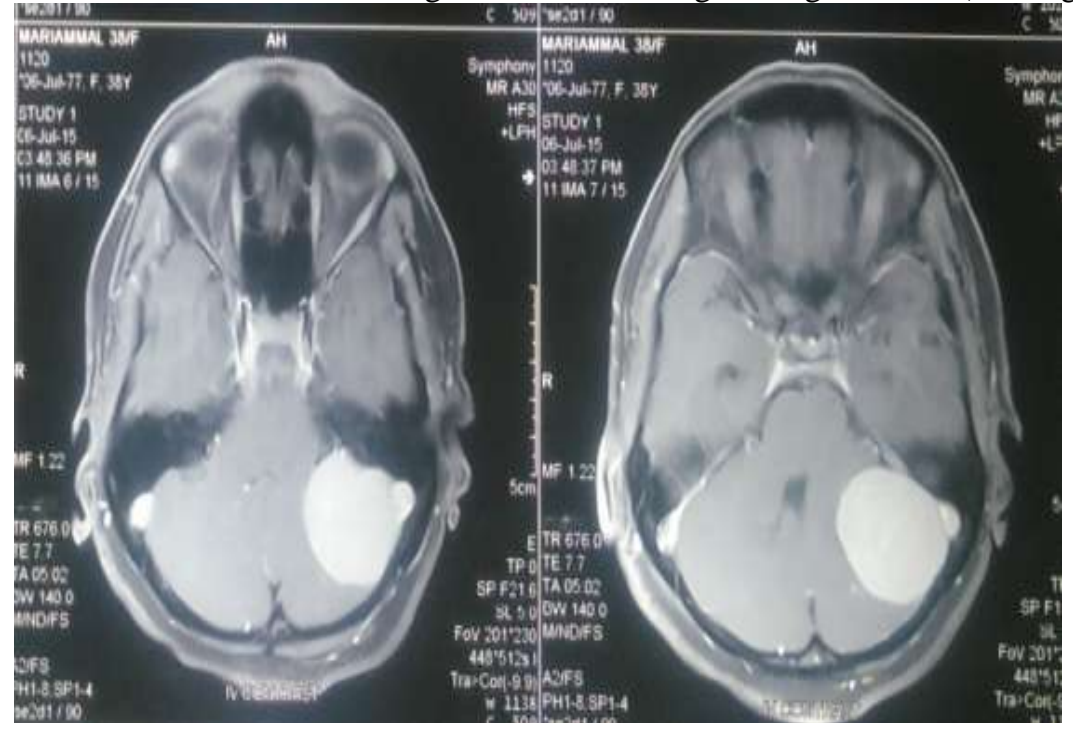

Figure 8: MRI Axial section showing contrast enhancing CP angle Tumor (Schwannoma)

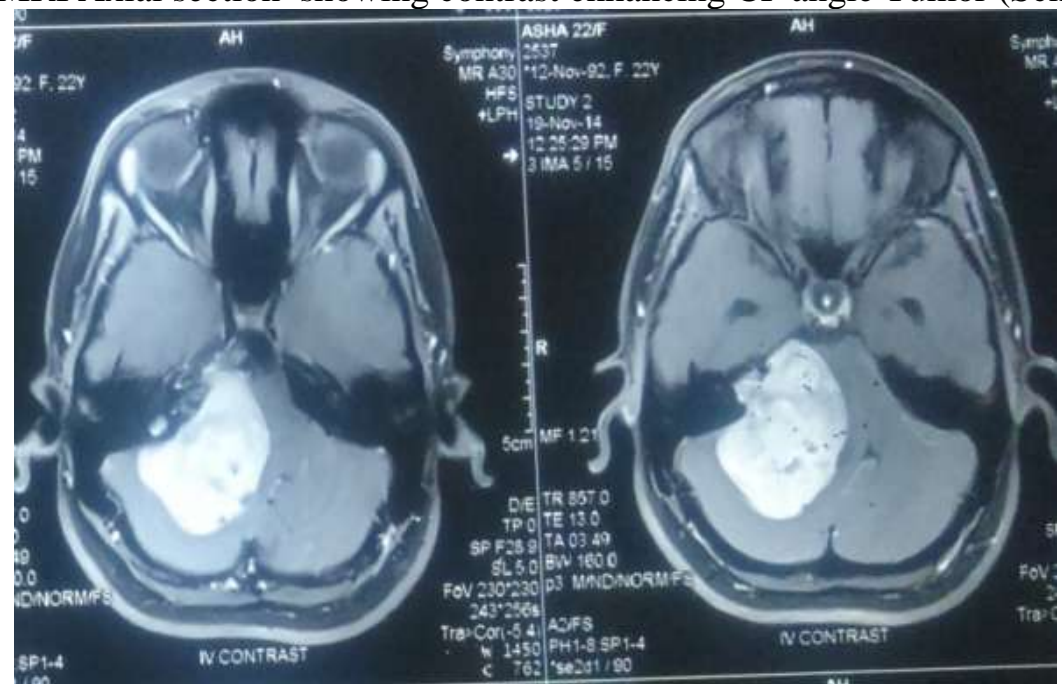

Figure 9: MRI Axial section showing midline cerebellar SOL

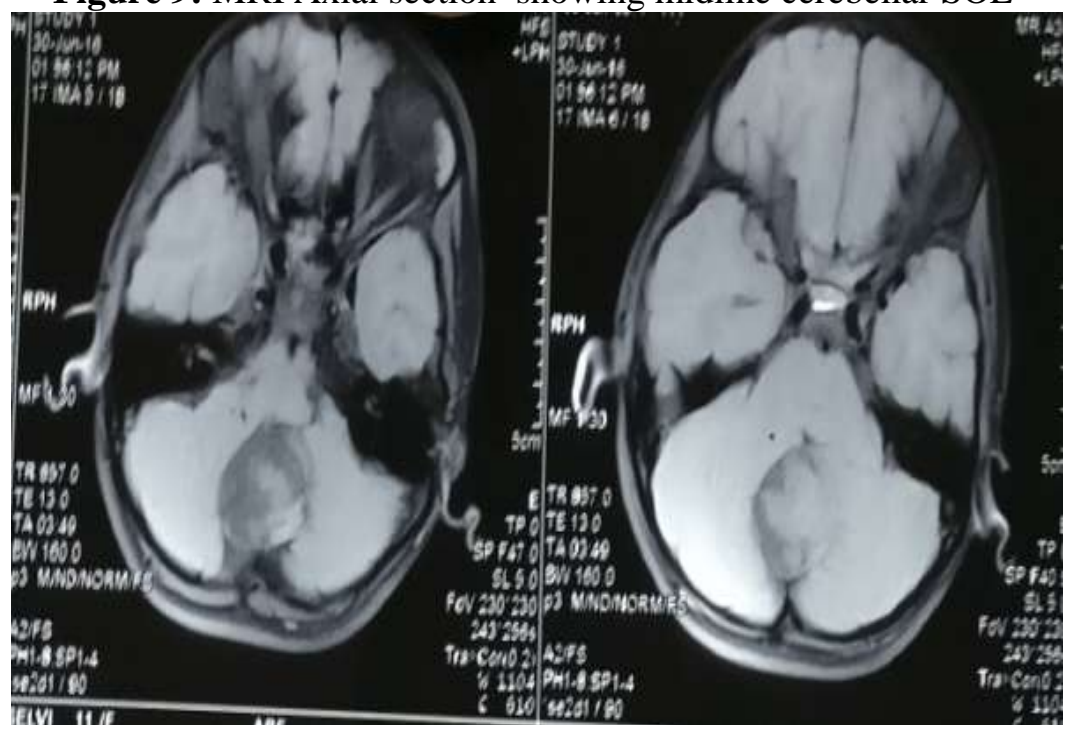

